\title{
The employment of graduates within small and medium sized firms in England
}

\author{
Trevor Hart1* and Paul Barratt ${ }^{2}$ \\ ${ }^{1}$ Newcastle University \\ 2University of Hull
}

\begin{abstract}
This paper reports a research study prompted by the uneven distribution of graduates between small and large businesses. In particular, it sought to understand the main drivers or impediments to recruitment of graduates by small and medium sized enterprises (SMEs) through an in-depth study of a matched sample of small firms employing and not employing graduates. It also sought to understand the nature of the benefits which might accrue to an SME from employing graduates. While some of the barriers can be attributed to 'market failure' in the sense that there were gaps in information available to SMEs and deficiencies in recruitment processes, others are cultural and concerned with the nature of the small business model.
\end{abstract}

Keywords: graduates, SMEs, recruitment, skills.

\section{Introduction}

In recent years, small businesse ${ }^{1}$ have been identified in both the policy and academic literature as having important roles in providing employment and in driving improvements in innovation and productivity. However, they are seen as operating under a number of constraints, including a lack of skills generally and shortages of the specific skills necessary for advancing technological and market penetration (SBS, 2004). At the same time, the supply of highly qualified workers in the labour force has been increasing, with the number of graduates in the workforce rising by two million between 1994 and 2004: around a third of a million graduates are added to the total each year ${ }^{2}$. In parallel, the nature of the work that graduates do has been changing (Purcell, et al, 2005). 
For the most part, graduates find jobs in larger enterprises and there is a steady increase in the proportion of graduates as firm size increases (LFS, 2003/4; Belfield, 1999; Williams and Owen, 1997). This gravitation to large firms is coupled with a bias towards the south of England: over a quarter of all graduates work in the south in large enterprises. There is thus, prima face, scope to meet the skills needs of small businesses and assist in the achievement of national employment and productivity policy objectives brought into sharp relief by the Leitch Review of Skills as "without increased skills, we would condemn ourselves to a lingering decline in competitiveness, diminishing economic growth and a bleaker future" (Leitch, 2006: 1) - by moving towards a more even regional distribution of graduates and improving the representation of graduates among the workforce of small businesses.

Why should this uneven distribution arise and persist? From the point of view of the graduate, the continued existence of a 'graduate premium' in earnings throughout a career (Elias and Purcell, 2003) suggests that they typically inhabit more favoured segments within the labour market, but it does not explain whether uneven distribution is a result of their responding to market signals, such as higher rewards on offer in larger firms, whether they are unaware of the nature of returns available from employment in small and medium sized enterprises (SMEs), or whether demand for their services from SMEs is deficient.

In a rational world, SMEs would recognise the returns to education and training and recruit graduates at the same rate as larger firms. Assuming that the asymmetry in recruitment does not reflect an asymmetry in need, the fact that they do not do so may be explained by some form of 'market failure', most obviously imperfections in information flows, rendering SMEs less aware of the benefits of employing graduates or the methods to be used to recruit and employ them. As SMEs are vying with larger firms for the services of graduates, they need to be able to adopt a competitive position: Williamson (2000) suggests that SMEs need to adopt a dual strategy of distinctiveness and isomorphism if they are to achieve the best recruitment outcomes. However, among the constraints that SMEs operate under may be institutional and structural disadvantage which limits their ability to compete on an equal footing with larger businesses.

This paper reports on a study which sought to better understand graduate employment in SMEs. It particularly focuses on identifying the motivations and barriers to graduate recruitment by SMEs and sought to document the actual contribution of graduates to the success of businesses. It reviews both the literature and research findings before reporting the conclusions from the study and identifying some policy implications.

\section{What do we know about graduate employment in SMEs?}

There is a very limited amount of research specifically focused on graduate employment in SMEs. Generally, research remains both fragmented and focussed on theory developed to interpret the graduate labour market in light of large company needs (Holden and Jameson, 2002): "understanding about the recruitment and utilization of graduates in SMEs is still in the twilight" (Holden, Jameson and Walmsley, 2007: 225). This skewed pattern of research perhaps reflects that most graduates are employed in large firms. The evidence of a relationship between firm size and graduate employment is not however completely consistent, with small firms being identified as having greater scope for growth and that growing firms are likely to turn to graduates to meet their needs for middle management skills (Blackburn et al, 2002; GIEU, 1998). 
There is some evidence that there are sectoral biases in graduate employment. A number of sources show concentrations of graduate employment in the higher end services (LFS; Williams and Owen, 1997; Harris and Reid, 2005). Conversely, the Federation of Small Business (FSB) biennial survey (2004) reported that, in its sample, the manufacturing and construction sectors have the smallest proportions of small businesses employing graduates. These sectoral patterns can be related to the subject discipline of graduates (MacDonald, 1999).

\section{Employer and graduate perceptions}

Imperfect and distorted knowledge of the benefits that employing graduates may bring has often been identified as a key factor inhibiting the recruitment of graduates by SMEs. Much of the suspicion and ignorance in the HE/small business relationship is likely to be caused or compounded by the lack of owner/manager experience of higher education, either directly or because SMEs are less likely to have graduates among their employees, and by the limited opportunities small business has to interact with HEls (AGR/BSEL, 2004; Williams and Owen, 1997; Holden and Jameson, 2002; Booth, 2004). This was a theme of the Lambert Review (2003) of business-university collaboration.

Doubts among SMEs about employing graduates appear in a number of forms. These include an inflated view of the costs; an inability to meet graduate expectations (partly based on a 'uniform' view of graduates) (Holden and Jameson, 2002: 273; Johnson et al, 1993); and the capacity of graduates to meet their needs. Rajan et al (1998) and Smith et al (2004) for example, note the suggestion that graduates are not equipped with the core skills to enable them to 'hit the ground running', while O'Brien highlights doubts that graduates will 'add value' to a business. A number of studies highlight a perception that graduates are deficient in initiative, interpersonal skills, business awareness and team working (Rajan et al, 1998; Cushlow, 1999; O'Brien, 1997).

Ignorance of the small business sector by graduates has also been identified as a barrier to recruitment by SMEs. For example, Mukhtar et al (1999) in their survey of 250 science and technology students in Manchester found that over 80 per cent of the sample had not considered employment in an SME, and thirty per cent were not willing to consider working in an SME when the possibility was suggested. The reasons for such antipathy can include, compared with larger firms: lower salaries and other benefits; lack of clearly defined 'graduate' positions; lack of formality in roles and career paths; lack of training opportunities; and parent and peer pressure (Jameson and Holden, 2000; FSB, 2004; NESS, 2004; Harris and Reid, 2005).

\section{The working of the graduate labour market}

However, there are a number of factors which can act to facilitate the recruitment of graduates by SMEs. First, not all SMEs have a negative perception of graduates (GIEU, 1998; Coopers and Lybrand, 1998; Brindley and Ritchie, 2000; Conway and Baines, 2000). Second, HEls are in some cases addressing factors which have inhibited graduate recruitment (Young and Morris, 2000). Third, there have been a number of initiatives at the regional level, promoted by Regional Development Agencies (RDAs), which have sought to improve links between SMEs and graduates and to generally improve the links between graduates seeking jobs and employers seeking graduates (see, for example, Allison, et al, 2003; Wilson, 2005). 
There have also been a number of changes in the nature of the graduate labour market, in part brought about by the increase in numbers of young people going through the higher education system and the accompanying decline in the number of 18 year old school leavers seeking entry to employment. Demand side factors mainly relate to a perceived need to recruit more highly skilled and qualified personnel in a number of sectors, including $\mathrm{IT}$, engineering design, sales and marketing, and finance and accounting. Among the concrete requirements identified were: a need for a higher level of skills, knowledge and performance, better analytical and problem-solving skills and greater adaptability (Mason, 2001).

According to Holden and Jameson, (2002: 273), there is little consensus about what constitutes a 'graduate job' but, drawing on an extensive programme of surveys and interviews with graduates seven years after graduating, Purcell and Elias (2004) have developed a new occupational classification for the graduate labour market. Their new classification identified four main categories of graduate employment, distinguishing particularly between Traditional graduate occupations, such as the established professions, and three other categories termed Modern graduate occupations (such as management where graduate entry has become the norm); New graduate occupations (such as marketing); and Niche graduate occupations (such as hospitality and leisure, where most workers do not have degrees but where specialist niches are developing).

Comparison of two cohorts of graduates (from 1995 and 1999) revealed that 'Employment in traditional graduate occupations was 4-6 per cent lower among the 1999 graduates than in the earlier cohort. A higher proportion of the 1999 graduates were employed in modern and new graduate jobs.' (Purcell et al, 2005: 94). Studies (Purcell et al, 2005; Mason, 2002) also suggest that a significant proportion - over 40 per cent - of graduates is over-qualified for the first job, but that this proportion declines over time: Purcell et al showed a reduction to 11 per cent after seven years. This pattern has remained broadly constant over a 15 year period.

\section{Labour market processes}

A study for the Small Business Service (SBS, 2002) suggests that there is a distinction to be made between two types of motivation or expectation when SMEs recruit graduates. It distinguishes between employers who recruit graduates for their specific professional or technical skills and those where a degree is seen as signalling the generic and transferable skills of a potential employee. For example, according to Perryman (2004) 'Finance and business service sector employers often value the high level, transferable skills of science and technology graduates, such as numeracy, analytical thinking, problem solving, computer literacy and data handling' (see also the Roberts Review, 2002).

There is relatively little study of the methods of graduate recruitment to SMEs. Williams and Owen (1997) and Holden and Jameson (2002) highlight the relative absence of long term thinking and the propensity to use informal networks for recruitment. The study by Purcell et al (2005), while not specifically focusing on SMEs, revealed some significant features about the routes graduates use to find employment. In particular, the importance of employment agencies as a means of finding work is highlighted, with 42 per cent of graduates using them as an aid to finding work. It is pointed out ( $p .82$ ) that they have become an increasingly significant player in the graduate labour market and there has been a growth in agencies dealing specifically with graduate employment, as well as those dealing with specific professions and industry sectors. Their use was more important for 
those finding work in modern, new and niche graduate jobs - and particularly non-graduate jobs - than it was for those taking up traditional graduate occupations. The study also confirms the finding of other work relating to the value of work placements and prior work experience in helping graduates find work: it has the effect of assisting to achieve 'more rapid assimilation into graduate-appropriate employment' (ibid, p. 84).

\section{Methodology}

As well as reviewing existing literature and data, the study used a large scale telephone survey to identify the characteristics of a sample of SMEs employing and not employing graduates. The research questions were then explored through a programme of in-depth face-to-face interviews with senior staff in a sub-sample of 80 SMEs, structured into matched pairs (employing/not employing graduates). When possible and practical, these interviews were supplemented by interviews with graduates employed by the firm, to further our understanding of their utilisation and impact. Following initial analysis, four follow up visits were conducted to further explore examples of significant impacts or processes. As well as improving understanding, in general terms, of graduate employment in SMEs, the study sought to address two main questions:

- what are the benefits to SMEs of employing graduates? and

- what are the main drivers or impediments to graduate employment in SMEs?

Characteristics of the sample are shown in Table 1.

Table 1: Profile of sample companies interviewed

\begin{tabular}{|c|c|c|c|c|c|c|c|c|c|c|c|c|}
\hline \multirow[b]{2}{*}{$\begin{array}{l}\text { Graduates } \\
\text { employed? }\end{array}$} & \multicolumn{3}{|c|}{ No. employees } & \multicolumn{3}{|c|}{$\begin{array}{c}\text { Age of business } \\
\text { (yrs.) }\end{array}$} & \multicolumn{2}{|c|}{ Sector } & \multicolumn{2}{|c|}{ Region } & \multicolumn{2}{|c|}{$\begin{array}{c}\text { Growth } \\
\text { aspirations }\end{array}$} \\
\hline & 5 to 9 & $\begin{array}{c}10- \\
24 \\
\end{array}$ & $\begin{array}{l}25- \\
249 \\
\end{array}$ & $1-2$ & $3-4$ & $\begin{array}{l}5 \text { or } \\
\text { more }\end{array}$ & $\begin{array}{c}\text { Manu- } \\
\text { facturing }\end{array}$ & Service & $\begin{array}{l}\text { Lond. \& } \\
\text { South }\end{array}$ & $\begin{array}{l}\text { rest of } \\
\text { Eng. }\end{array}$ & Yes & No \\
\hline Yes & 9 & 11 & 20 & 6 & 19 & 15 & 15 & 25 & 8 & 32 & 36 & 4 \\
\hline No & 13 & 11 & 16 & 7 & 15 & 19 & 15 & 25 & 11 & 29 & 32 & 8 \\
\hline
\end{tabular}

Prior to each interview, the basic profiles of firms obtained through the telephone interviews were extended by examining web sites and accounting information. Interviews fleshed out the profiles to develop a fuller understanding of the structure and operating style of the businesses, to provide a context for a detailed exploration of attitudes and approaches to graduate recruitment. All interviews were recorded and transcribed.

\section{Research findings}

\section{Broad patterns of difference}

Analysis of the data from the interviews with 80 SMEs provided little evidence of any substantive differences between the two sets of similar companies that do and do not 
employ graduates. In itself, this may well be a very significant finding, in that there is no typology of SMEs that suggests itself that would have significant predictive value. What the study did show was that over 70 per cent of the decision makers in the companies that employed graduates were themselves graduates, but that the corresponding figure for companies that do not employ graduates is less than 40 per cent. It also found that companies that employ graduates consistently gave a realistic figure for a starting salary whereas those not employing graduates consistently over-estimated the figure.

\section{Value added by graduates}

Developing a better understanding of the benefits that graduates bring to SMEs was a key objective for this project and a detailed element of each interview. For this reason, the process through which graduate benefits are realised within SMEs were broken down to explore its workings in detail. The analytical framework involved a three stage 'model' which focuses on the qualities that graduate employees hold as a direct result of undertaking a degree, the mechanisms by which these qualities are utilised within the workplace, and lastly, the positive outcomes that result. Figure 1 outlines the model used to analyse the qualitative data obtained from the firms interviewed.

Figure 1: Three stage model of graduate benefits to SMEs

\section{QUALITIES}

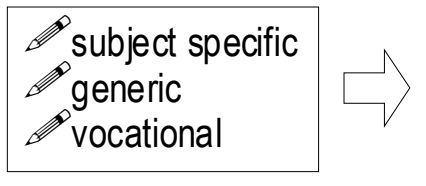

MECHANISMS

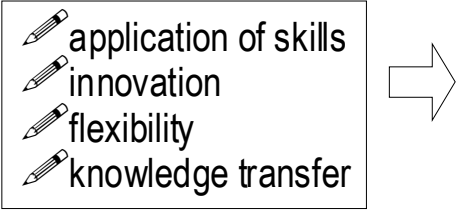

OUTCOMES

productivity
sales
savings
growth
competitiveness

Most of the 40 firms that employed graduates felt able to identify benefits gained from their graduate recruits, but the evidence was illustrative rather than systematic. Clearly, the extent to which any benefits are realised will depend on a range of individual and contextual factors but a number of themes emerged during interviews.

\section{Qualities}

Many occupations or professions are catered for by subject specific degree courses. The employment of graduate in a relevant discipline in these positions was often found to result in both immediate and long-term benefits for a business. So, an IT firm in Yorkshire found "graduates that we target have trained in areas directly relevant to the work we undertake, so minimal training is required: [they] tend to hit the ground running when employed", while a Midlands manufacturing company felt that a graduate in their HR department offered "significant and long-term" benefits.

On the other hand, generic skills held by graduates, acquired formally through study, and informally through personal development while at university, were also seen as valuable by some SMEs. Value was felt to accrue to the business through factors such as ability to learn quickly, to see the 'bigger picture', to be able to work independently and to 
occasionally add an element of innovation: "graduates bring new ideas and motivation, a business can go stale, you sometimes need some young blood (graduates) to shake things up and get things going in the right direction again" (manufacturing firm, South of England).

Vocational experience gained through university placements, work undertaken whilst at university to help fund studying and jobs held prior to becoming a student was felt to be a positive factor in helping to realise the potential benefits of employing graduates, partly because it helped them "hit the ground running". Indeed, in some cases it helped overcome reservations about employing graduates: "I would never take on a graduate who had not had any work experience at all. I like the reassurance of a positive reference from a previous employer and knowledge that the graduate can transfer academic knowledge to workplace success" (Communications firm, East Midlands).

\section{Mechanisms}

Although benefits were often realised by the straightforward application of professional skills, in other instances the mechanisms were less direct. Attributes such as critical or creative thinking became apparent through gains in efficiency or effectiveness of working practices. In a number of cases, working in a small business gave graduates an opportunity to build a role for themselves and the outcome of this was also seen as a benefit to the business, in the form of improved products or processes. In a wider sense, knowledge transfer was recognised as a benefit by a number of businesses, both in the sense that a new graduate brought knowledge of new approaches and also that they came with a set of academic and professional linkages which could be cultivated at appropriate times.

\section{Outcomes}

A number of specific examples were cited of graduates improving business results. These included: gains in productivity ( 7 of the 40 firms); identifying and introducing processes which resulted in savings ( 8 firms); and driving sales (38 firms) and growth (6 firms). Less concrete benefits, such as adding prestige to the business and to customer confidence, were seen as helping to increase business competitiveness ( 9 firms): "having a wide range of skills is also a selling point for the company, as far as sales and marketing are concerned. When people see that we have high profile members of staff, it helps improve the company's image." (MD, manufacturing firm, Yorkshire).

Examples of positive, concrete outcomes played an important role in the graduate recruitment decision. They helped form perceptions and shape assumptions about the impact of employing graduates. In the absence of formal and structured knowledge of the graduate labour market - a feature which was often allied to the absence of a formal HR function within a business - such perceptions proved to be decisive in forming recruitment policies and practices. However, some interviewees suggested that, for particularly the less tangible benefits to become a driver for graduate recruitment, the business needed to be of a certain size. So the FD of a Northern service company with a propensity to recruit graduates identified it as being at a cusp - employing 40 people was not big enough to consider taking on graduates to develop/train as part of a middle management function, but soon it would get there: such graduate positions would not be so driven by the imperative of meeting an immediate need but more by a longer-term strategic purpose. 


\section{Businesses not employing graduates}

While some of the 40 companies that did not employ graduates recognised their potential contribution, many felt they lacked "graduate" positions. However, evidence from similar firms and competitors employing graduates cast doubt on how far this was a complete explanation. The other reasons given for not employing graduates fell into three broad groups. First, there were what might be termed cultural and knowledge barriers which were particularly prevalent with the many owners and managers who had not recruited graduates before. They lacked knowledge of graduate skills and attributes and had little practical conception of the potential benefits of employing graduates. They also lacked awareness of how to go about recruiting graduates and the appropriate levels of salary to offer. Second was a group of employers who had negative perceptions of graduates, sometimes amounting to an "anti-graduate" stance, often based on a past "bad experience.' As well as expressing fears about the length of time graduates would stay, there was also evidence of doubts about the basic suitability of graduates for their business: "They don't even have basic office skill and don't want to get their hands dirty" (Manufacturing firm, South East). Finally there were firms who took a more rational approach to the question, exemplified by the HR manager of manufacturing firm in the south of England. She emphasised that graduates would be judged on whether they fitted the 'person specification' for the job and this was not demonstrated by a degree alone. She needed to understand their motivation, their practical as well as academic skills, and whether they would fit the company: "With a smaller business you are far more conscious of the culture of the organisation, far more conscious of the personalities of the people you are with. In a big company with a formal training scheme, you trot around, sort of anonymous, but they're far more visible here. It's fish and pools isn't it".

\section{Analysis}

\section{A typology of businesses}

Analysis of interview data revealed few clear patterns by sector, region or occupation, but suggested a distinction between what we have termed 'strategic employers', 'occasional employers' and 'accidental employers'. This typology is elaborated in Table 2 but it should be remembered that the descriptors used in the analysis represent 'central' positions along a gradient, from those SMEs which deliberately and habitually employ graduates to those which may not even know that they have one on their staff. In reality many firms deviate in some way from these ideal types, taking certain elements from the other two categories. 
p. 9. The employment of graduates within small and medium sized firms in England

Table 2: Graduate recruiter typology

\begin{tabular}{|c|c|c|c|c|c|}
\hline $\begin{array}{l}\text { Type of } \\
\text { Graduate } \\
\text { recruiter }\end{array}$ & Description & Characteristics & $\begin{array}{l}\text { Type of } \\
\text { graduate } \\
\text { recruitment }\end{array}$ & $\begin{array}{l}\text { Type of } \\
\text { graduate } \\
\text { occupation } \\
\text { present }\end{array}$ & $\begin{array}{l}\text { Number in } \\
\text { graduate } \\
\text { recruiter } \\
\text { sample } \\
(n=40)\end{array}$ \\
\hline Strategic & $\begin{array}{l}\text { Commitment to } \\
\text { recruiting graduates. } \\
\text { Recognition of } \\
\text { graduate skills and } \\
\text { benefits. Presence of a } \\
\text { graduate in the } \\
\text { recruitment decision } \\
\text { process ( } 73 \text { per cent } \\
\text { cases). Strong } \\
\text { likelihood that degree } \\
\text { would be specified in } \\
\text { personal spec for } \\
\text { position. Graduate } \\
\text { recruitment decisions } \\
\text { driven by company } \\
\text { strategy and skill } \\
\text { requirements. }\end{array}$ & $\begin{array}{l}\text { organised and forward } \\
\text { looking; led by business } \\
\text { plan } \\
\text { - } \text { seeking growth through } \\
\text { innovation and } \\
\text { investment } \\
\text { - } \text { awareness of benefits } \\
\text { of employing graduates } \\
\text { shaped recruitment } \\
\text { strategies } \\
\text { few 'bad' experiences } \\
\text { with graduate staff. }\end{array}$ & $\begin{array}{l}\text { External } \\
\text { requirement, } \\
\text { established } \\
\text { capacity } \\
\text { building, } \\
\text { technology } \\
\text { transfer }\end{array}$ & $\begin{array}{l}\text { Modern } \\
\text { graduate and } \\
\text { new graduate } \\
\text { occupations }\end{array}$ & 8 \\
\hline Occasional & $\begin{array}{l}\text { Recognition of } \\
\text { graduate skills and } \\
\text { potential benefits. } \\
\text { Graduates favoured at } \\
\text { short-listing and } \\
\text { interview stage. } \\
\text { Unlikely that degree } \\
\text { would be specified in } \\
\text { personal spec for } \\
\text { position. Graduate } \\
\text { recruitment decisions } \\
\text { often informed by } \\
\text { experience. }\end{array}$ & $\begin{array}{l}\text { no deliberate graduate } \\
\text { recruitment policy but } \\
\text { positive view of } \\
\text { graduates } \\
\text { - } \text { existing graduates in } \\
\text { key management or } \\
\text { R\&D positions } \\
\text { while recognising } \\
\text { benefits of graduates, } \\
\text { mainly an 'experience } \\
\text { focused' recruiter } \\
\text { - mainly smaller firms. }\end{array}$ & $\begin{array}{l}\text { All types of } \\
\text { recruitment } \\
\text { present }\end{array}$ & $\begin{array}{l}\text { New graduate, } \\
\text { niche } \\
\text { graduate, and } \\
\text { non-graduate } \\
\text { occupations }\end{array}$ & 18 \\
\hline Accidental & $\begin{array}{l}\text { No commitment to } \\
\text { further graduate } \\
\text { recruitment. Mixed } \\
\text { views (if any) } \\
\text { concerning } \\
\text { value/benefit of } \\
\text { (potential) graduate } \\
\text { employees. }\end{array}$ & $\begin{array}{l}\text { - } \text { no graduate policy or } \\
\text { ambivalence to their } \\
\text { value; existing } \\
\text { graduates in one or two } \\
\text { key management } \\
\text { positions } \\
\text { - other graduates in 'non } \\
\text { graduate' jobs but } \\
\text { evidence of possibility } \\
\text { of progressing to a } \\
\text { 'graduate' role. }\end{array}$ & Accidental & $\begin{array}{l}\text { All types of } \\
\text { graduate } \\
\text { occupation } \\
\text { present. Over } \\
\text { representation } \\
\text { of graduates } \\
\text { employed in } \\
\text { non-graduate } \\
\text { positions. }\end{array}$ & 14 \\
\hline
\end{tabular}


Businesses not employing graduates also revealed shared characteristics. A number of firms simply felt that they did not require a skilled workforce - for example, some manufacturing firms in the sample had an established market, used unskilled production practices and felt they did not require graduate skills to manage, operate or sell the resultant products. Similarly, within the service sector, higher skilled personnel were not felt to have a place. Occasionally, some of these firms reported that they had employed graduates who were identifiably under-employed: they received the same pay as their nongraduate colleagues.

Most companies in this category could not see that they had any suitable roles for graduates. This was particularly so amongst businesses with 20 or fewer employees, many of which did not employ graduates because they could only employ staff who they saw as "ready to go" and "get out into the field and meet customer needs". Some of these employers considered the roles within their firms to be graduate-level, but did not consider new graduates as viable employees because of their perception that they lacked vocational skills and "market savvy". Most of these negative perceptions were based on personal opinion and hearsay, rather than actual experience with a graduate employee.

\section{The graduate recruitment process in SMEs}

The methods of recruitment within the 80 sampled firms varied widely, but most lacked a structured approach. This was most apparent in the firms employing 20 or fewer staff, many of which claimed to lack the resources necessary to have a dedicated member of staff responsible for recruitment. In general, the larger SMEs were more likely to have some type of recruitment/human resources strategy, but it was rarely integrated with the business planning process. Recruitment was often undertaken in an ad hoc manner reflecting short term pressures and the experience of individuals. Personal preference and perceptions of the staff responsible constituted major drivers of recruitment decisions.

The predominant methods of recruitment were the use of agencies and informal networks. Few firms had made use of established university careers services, or regional graduate recruitment and retention schemes, and many had no knowledge of the latter. It is important to recognise that most of the recruitment discussed by respondents prioritised "staff who could be 80 per cent effective immediately". Few had any specific intention of recruiting new graduates; rather they had a task in mind that needed doing, possibly by someone with graduate-level abilities.

Within the sample of 80 firms, 27 out of the 40 graduate employers had used recruitment agencies. A further 20 out of the 40 non-graduate recruiters also used the services of recruitment agencies. Although agencies could represent a costly option, they were seen as offering a number of benefits including the saving of time - especially where a productive relationship was established with an agency - and the option of "try before you buy', whereby firms kept the staff as contract employees until their worth was assessed: if they were satisfactory, they could be taken on as permanent staff.

New graduates were seldom the target for recruitment when using agencies' services; rather, they were sent to the firm when they best met the job specification of the vacancy. Most of the graduates recruited via this route were therefore either those with some postgraduation work experience, or graduates applying for what were not necessarily 'graduate jobs'. Generally, agencies are becoming an important route into employment for new graduates. This may reflect a number of factors including: 
- the weakness of existing mechanisms linking SMEs and new graduates

- financial pressures leading to new graduates returning home to seek their first post, away from their university careers services

- uncertainties among graduates about their ultimate job destinations, leading to the use of agencies as a general gateway to a choice of work, not necessarily permanent (i.e. graduates echo the employers 'try before you buy' approach).

Informal networks were used by a number of the businesses interviewed. This was sometimes based upon cost grounds, when both agencies and advertising were regarded as too expensive. Sometimes informal methods were seen as a way to reduce risk in recruitment, whereby a recommendation from a trusted personal network is seen as the best method of finding the right person. On other occasions, firms had direct approaches from prospective employees and these were retained until posts were available.

\section{Conclusions and possible policy implications}

While the research did not reveal any clear spatial or sectoral pattern in graduate employment in SMEs such that a useful typology of employers could be constructed, it did indicate that graduates were more likely to be recruited by firms placing a greater stress on business planning and showing more foresight. These were firms which we termed 'strategic employers'. Our other categories, of 'occasional' or 'accidental' employers, had a less focused approach to recruitment and had a much less clear appreciation of the potential contribution of graduates to their business. While the research could not provide a definitive or quantified assessment of the contribution of "graduate-ness" to business success, amongst our sample of SMEs employing graduates were to be found a significant number of positive employer assessments of the value of graduates to their business. The majority of these assessments emphasised developmental benefits, such as aiding growth or facilitating innovation, rather than carrying out existing processes more effectively. Intuitively, it is more likely that such benefits will be perceived and realised by more forward looking - strategic - firms.

Firms which did not recruit or employ graduates tended to suffer a number of misconceptions over uncertainties about the graduate labour market, often associated with a lack of experience of higher education. These included: lack of information about salaries and costs; concern over retention; doubts about vocational readiness of graduates; and lack of understanding about what might be a 'graduate job': in a number of cases, there was an active presumption against recruiting graduates. However, some of these uncertainties were shared by our 'occasional' or 'accidental' employers.

Given the steady increase in the number of graduates it is likely and perhaps necessary that more will find employment in SMEs. Given the continued stress in government policy on improving levels of skills it is important that SMEs play a part in any general 'up-skilling' of the workforce, although Leitch lacks any specific SME perspective. However, the barriers to more small businesses recognising and realising the benefits of recruiting graduates is in many respects an aspect of generic weaknesses of small business management and as such will not be addressed successfully by initiatives narrowly focused on labour market issues. While the management of businesses in our sample might not be 'strategically myopic' (Mazzarol, 2001), most took a functional rather than the 
developmental view of their business that is perhaps necessary to make them active players in the graduate labour market.

However, there are a number of practical barriers to graduate recruitment. Many SMEs in the sample were handicapped by a weak or non-existent human resource/recruitment capability, limiting their ability to reach out to the sometimes unfamiliar graduate labour pool. In part, this prompts a reliance of recruitment agencies, which are becoming an important route into work for graduates. The firms showed a low awareness of the mechanisms - such as those operated through RDAs - that are developing to help them recruit graduates. The inherent difficulty of linking over 4 million dispersed SMEs with a large numbers of equally dispersed graduates or lightly resourced university careers departments suggests that these impediments or 'market failures' will not easily be tackled.

A major element of 'market failure' inhibiting graduate recruitment is that of lack of knowledge and appreciation of the return to investment in graduate skills. The research suggests that this is both a product of an absence of evidence perceived as relevant to the small firm and of any mechanisms that can convey such information effectively particularly ones which will enjoy credibility with owners and managers of SMEs. While the increase in the number of graduates employed in SMEs - accidentally of deliberately - is likely to lead to a diffusion in the appreciation of the potential benefits of employing graduates, positive engagement by the range of players in the graduate recruitment market will be necessary if the process is to be speeded up. However, the barriers to increased graduate employment in SMEs are both cultural and practical: addressing the 'market failure' associated with gaps in information concerning potential benefits of graduate employment or adapting and developing recruitment structures will not, by itself, be sufficient.

\section{Notes}

1 The most widely used definition, and that used by the UK Small Business Service (SBS), considers an SME to be an enterprise with fewer than 250 employees; such businesses account for about four in ten jobs in the whole economy: this is the definition adopted in this research.

2 Data from HESA and LFS.

The work on which this paper is based was funded by the Small Business Service; however, the views reported here are solely the responsibility of the authors.

* Correspondence Address: Trevor Hart, School of Architecture, Planning \& Landscape Newcastle University, Newcastle, NE1 7RU, UK. Email: t.j.hart@newcastle.ac.uk. 


\section{References:}

Association of Graduate Recruiters/Bartlett Scott Edgar Recruitment Solutions (AGR/BSEL) (2004) Anatomy of a Graduate Recruiter Graduate Recruiter, April 2004. Warwick: Association of Graduate Recruiters.

Allison, G., Charles, D., Conway, C., Quinn, P. and Stone, I. (2003) Evaluation of graduate retention programmes in the North East of England. Newcastle: One NorthEast.

Belfield, C. R. (1999) The Behaviour of Graduates in the SME Labour Market: Evidence and Perceptions. Small Business Economics, 12, 3, 249-259.

Blackburn, R., Hart, M. and Stokes, D. (2003) Unpacking Small Business Performance: An Analysis of Enterprise, Strategy and Owner-Manager Factors Using Multivariate Techniques. Presented at the 26th ISBA National Small Firms Policy and Research Conference SMEs in the Knowledge Economy.

Booth, J. (2004) Get Ahead: Supplying high level skills to smaller companies. Loughborough: East Midlands Universities Association: University of Loughborough.

Brindley, C. and Ritchie, B. (2000) Undergraduates and small and medium-sized enterprises: opportunities for a symbiotic partnership? Education and Training, 42, 9, 509-517.

Conway, C. and Baines, S. (2000) How do small and medium sized enterprises become knowing firms? The role of graduates in the transfer of knowledge and skills. 24th ISBA National Small Firms Policy and Research Conference.

Coopers and Lybrand (1998) Using Graduate Skills: Final Evaluation Report. Online at http://www.dfes.gov.uk/dfee/hege/ugseval/ugseval.htm, downloaded November 2004.

Cushlow, F. (1999) North West Small and Medium Sized Enterprise Employers Needs and Expectations of Higher Education. DfEE/HEQE.

Elias, P. and Purcell, K. (2004) Is Mass Education Working? Evidence from the Labour Market Experiences of Recent Graduates. National Institute Economic Review, 190, 60-74.

FSB Biennial Membership Survey (2004) Lifting the Barriers to Growth in UK Small Businesses. Professor Sara Carter, Professor Colin Mason, Dr Stephen Tagg, Hunter Centre for Entrepreneurship, Strathclyde Business School, University of Strathclyde http://www.fsb.org.uk/documentstore/filedetails.asp?ID=38

GIEU (Graduates into Employment Unit) (1998) Beyond Work Experience: Maximising the impact of graduates on small business competitiveness. Liverpool, University of Liverpool.

Hanage, R., Johnson, D. and Mullein, D. (2004) Employing Graduates for Growth. Durham: Durham University Business School. Downloaded at www.graduatesforgrowth.org.uk $\angle$ reference/employing graduates for growth.doc on 28/11/2004.

Harris, R. and Reid, R. (2005) Graduate employment and training in Northern Ireland SMEs: an overview using the 2000 Labour Force Survey. Industry and Higher Education, 19, 1, 55-63.

Holden, R. and Jameson, S. (2002) Employing graduates in SMEs: towards a research agenda. Journal of Small Business and Enterprise Development, 9, 3, 271-284.

Holden, R., Jameson, S. and Walmsley, A. (2007) New graduate employment within SMEs: still in the dark? Journal of small business and enterprise development, 14, 2, 211 227.

Jameson, S. and Holden, R. (2000) "Graduateness" - Who Cares? Graduate Identity in Small Hospitality Firms. Education and Training, 42, 4, 264-271. 
Johnson, S. et al (1993) Graduate retention and the regional economy. Entrepreneurship and the Regional Economy, 5.

Lambert, R. (2003) Lambert Review of Business-University Collaboration: Final Report Norwich: HMSO.

LFS - Labour Force Survey: available on-line via http://www.statistics.gov.uk/STATBASE/Source.asp?vlnk=358.

Leitch, Lord (2006) Prosperity for all in the global economy - world class skills. London: HM Treasury.

MacDonald, C. (1999) After Graduation - What Next? An Analysis by Subject Area of Study. Manchester: The Enterprise Centre.

Mason, G. (2001) The mix of graduate and intermediate skills in Britain: what should the balance be? Journal of Education and Work, 14, 1, 5-27.

Mason, G. (2002) High skills utilisation under mass higher education: graduate employment in services industries in Britain. Journal of Education and Work, 15, 4, 427-456.

Mazzarol, T. (2004) Strategic management of small firms: a proposed framework for entrepreneurial ventures, cited in Small business owners: too busy to train? Journal of small business and enterprise development, 14, 2, 294-306.

Mukhtar, S. M., Oakey, R. and Kippling, M. (1999) Utilisation of science and technology graduates by the small and medium-sized enterprise sector. Education and Training, 41, 9, 42-43.

National Employers Skills Survey (NESS) (2004) National Employers Skills Survey 2003: Key Findings. London: Learning and Skills Council.

O'Brien, G. (1997) Graduates and Management Development in SMEs: Findings from Northern Ireland. Small Business Enterprise Conference.

Perryman, S. et al (2004) The IES Annual Graduate Review: 2003 Update. Business as Usual? Trends in Student and Graduate Numbers. IES Report 399: Downloaded at http://www.employment-studies.co.uk/summary/summary.php?id=399

Purcell, K. and Elias, P. (2004) Seven years on: graduate careers in a changing labour market. Warwick: IES.

Purcell, K., Elias, P., Davies, R. and Wilton, N. (2005) The Class of '99: A study of the early labour market experience of recent graduates. DfES Research Report No. 691 Nottiingham: DfES Publications.

Rajan, A., Chapple, K. and Battersby, I. (1998) Graduates in Growing Companies: The Rhetoric of Core Skills and Reality of Globalisation. Tunbridge Wells: Centre for Research in Employment and Technology in Europe.

Small Business Service (2002) Making a difference - The contribution of graduates to small business success Report to the Small Business Service, by Dr Rick Holden, Stephanie Jameson, Professor David J Parsons. URN 03/868, December 2002.

Small Business Service (2004) A government Action Plan for small business: The evidence base. London: DTI.

Smith, H. et al (2004) Briefings on Employability: Issues for Employers. On-line at www.Itsn.ac.uk/ESECT>EmployabilityBriefings. Downloaded, November 2004.

Williams, H. and Owen, G. (1997) Recruitment and Utilisation of Graduates by Small and Medium Sized Enterprises. DfEE Research Report No.29. Sheffield: Department for Education and Employment.

Williamson, I. (2000) Employer legitimacy and recruitment success in small businesses. Entrepreneurship Theory and Practice. Fall 2000, 27-42. 
p. 15. The employment of graduates within small and medium sized firms in England

Wilson, F. (2005) Three Years On...A Survey of the Early Career Paths of the Graduates of 2001 from the Yorkshire Universities Graduates. Yorkshire: Yorkshire Universities Leeds (report available at: www.graduatesyorkshire.info/2001-report.pdf).

Young, Z. and Morris, H. (2000) An Holistic Approach to the Use of Labour Market Intelligence (LMI) in HE Strategic Planning. Bolton: Bolton Institute. 